\title{
Right funicular hydrocele accompanied by in adverted lateral inguinal hernia finding in geriatric male patient during operation: a case report
}

\author{
Dewa Gede Sudiatmika1 ${ }^{1}$, Gusti Ayu Agung Bella Jayningrum²*
}

\author{
${ }^{1}$ Department of Urology, Sanjiwani Hospital, Bali, Indonesia \\ ${ }^{2}$ Department of General Surgery, Sanjiwani Hospital, Bali, Indonesia
}

Received: 07 January 2021

Accepted: 06 February 2021

\section{*Correspondence:}

Dr. I. Gusti Ayu Agung Bella Jayningrum,

E-mail: bjayaningrum@gmail.com

Copyright: (c) the author(s), publisher and licensee Medip Academy. This is an open-access article distributed under the terms of the Creative Commons Attribution Non-Commercial License, which permits unrestricted non-commercial use, distribution, and reproduction in any medium, provided the original work is properly cited.

\begin{abstract}
Lateral hernia is caused by patent or reopening of processus vaginalis that lead herniation of abdominal content into scrotal sac. These defects can cause atypical presentation of indirect inguinal hernia along with hydrocele. We present a case of a male 78-year-old with chief complain of painless swelling on right scrotum that gradually getting bigger since a year ago. During the examination we found trans-illuminable mass in the right scrotum along with protrusion of bowel contents at the inguinal region. Patient underwent herniotomy with mesh installation to fix the lateral inguinal hernia and then followed by hydrocele removal with Jaboulay's technique. Prognosis of this patient is believed to be good. We have presented a case of a geriatric patient with right lateral inguinal hernias with encysted hydrocele which is a presentation that could be happen due to anatomy of the inguinal ring. This patient underwent herniotomy with mesh installation to fix the lateral inguinal hernia and this procedure maintains the principle of tension-free posterior wall, hence preventing recurrence. Then followed by hydrocele removal with Jaboulay's technique to prevent any complications such as testicular atrophy, haematocele and pyelocele. Prognosis of this patient is believed to be good.
\end{abstract}

Keywords: Funicular hydrocele, Lateral inguinal hernia, Geriatric male patient

\section{INTRODUCTION}

Medial and lateral hernias both have common and different etiologies. Risk factors to develop both lateral and medial hernias are older age, a low BMI, and inguinal hernia susceptible genes have been identified that also are involved in connective tissue homeostasis. Even though connective tissue alteration is confirmed in both hernia subtypes, medial hernias appear to have a more profound alteration. ${ }^{1}$ Patent or reopening of processus vaginalis and increased cumulative occupational mechanical exposure are risk factors to develop lateral hernias. And, failure of closing processus vaginalis can lead to abdominal herniation into the scrotal sac. Patients most commonly present with an inguinal mass due to a defect in the deep inguinal ring. However, these defects can cause atypical presentation of indirect inguinal hernia along with hydrocele. ${ }^{2}$ Hydrocele is a collection of serous fluid between tunica vaginalis parietalis and visceralis. It may arise in the spermatic cord in males or canal of neck in females due to failure of closing processus vaginalis along with reduced fluid reabsorption. Etiologically, hydrocele is usually idiopathic but, in some cases, could be secondary to infections testicular torsion, tumor or trauma. ${ }^{3}$ The diagnosis is essentially clinical, but where doubt exists, scrotal ultrasound can be used to differentiate it from other scrotal lesions. ${ }^{4}$ Controversies regarding treatment of hydrocele such as aspiration of fluid and injection of sclerosants has been described, but associated with high rate of infection and recurrence and hydrocelectomy remains the treatment of choice for the management of hydroceles. 5 


\section{CASE REPORT}

\section{History and examination}

A 78 years old male with chief complaint of painless swelling on right scrotum that gradually getting bigger since a year ago. Patient denied any other associated complaints such as fever, nausea, vomiting, losing appetite, loose bowel movements or any urinary tract symptoms like dysuria, frequency, nocturia and hesitancy. Patient denies any significant past medical history, smoking, alcohol drinking and allergy.

We found trans-illuminable mass adjacent to the right scrotum. In addition, at the inguinal region, there was protrusion of bowel contents which was confirmed when asked to cough or stand up. Patient denies any pain or tenderness in the inguinal area. Remainder of the exam was non-significant. Scrotal ultrasound demonstrated cystic fluid accumulation on right scrotum. Laboratory findings such as complete blood count, basic metabolic panel and liver function tests were within normal limit.
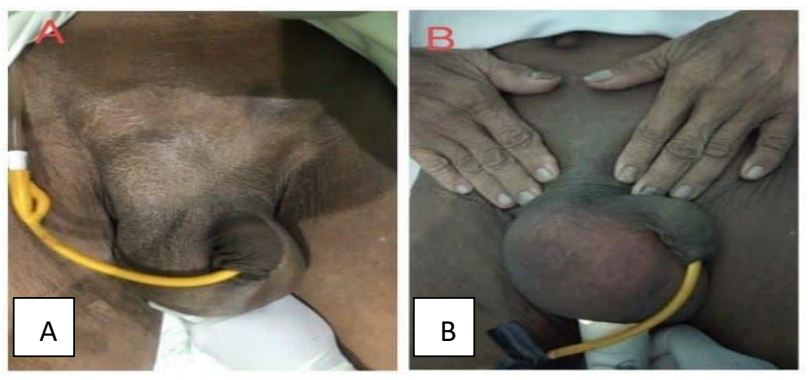

Figure 1: Pre-op picture of patient. A: Lateral inguinal hernia as profound mass on the inguinal. $B$ : Hydrocele as trans-illuminable mass on the right scrotum.

\section{Intervention and outcomes}

Upon surgical exploration right scrotal swelling with lateral inguinal hernia and encysted funicular hydroceles were found. We did herniotomy with mesh that was placed over the superficial inguinal ring along with tightening of the deep inguinal ring. And then, hydrocele was excised with Jaboulay's technique.
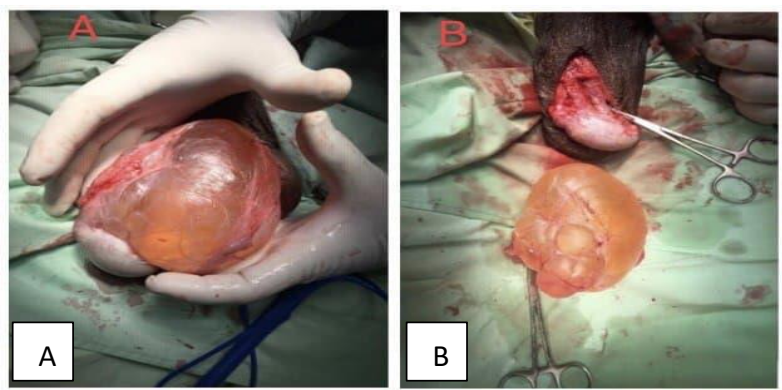

Figure 2: Durante op picture. A: Hydrocele of the spermatic cord. B: Excised hydrocele.

\section{DISCUSSION}

In most cases, hydroceles are idiopathic, but in some cases, it can be secondary to testicular torsion, cancer, trauma, as well as diseases such as orchitis, epididymitis, tuberculosis or filariasis. ${ }^{5}$ Lack of fluid reabsorption from the remnant piece of tunica vaginalis around the scrotal sac is typical causative of adult hydroceles. There are two basic types of hydroceles which are caused either by: incomplete closure from proximal to distal end of processus vaginalis during the descent of testis and via failure of closure of proximal processus vaginalis with an opening to the peritoneal cavity which can present with inguinal lymphadenopathy and mimic an inguinal hernia. ${ }^{6}$ Due to this problem, can cause atypical presentation of lateral inguinal hernia along with hydrocele.

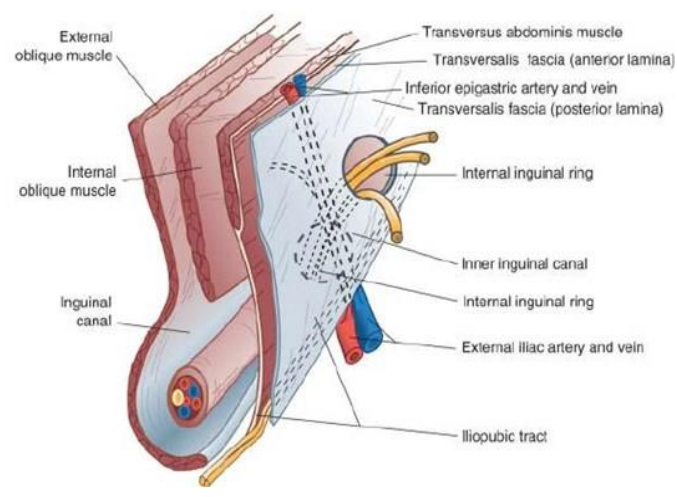

Figure 3: Anatomy of inguinal canal and its surrounding structure. ${ }^{2}$

We did herniotomy with mesh and hydrocele excision was performed with Jaboulay's technique. Herniotomy was performed with gently separating the sac from the internal spermatic fascia from fundus to the neck. It then incised and the contents are pushed into the abdominal wall. The neck of sac is transfixed and twisted to completely empty the contents and then the sac is excised. Later, mesh is placed into posterior wall of the inguinal canal, then wound is closed layer by layer provided a new superficial ring is created for the cord structure to enter the scrotum. ${ }^{8}$

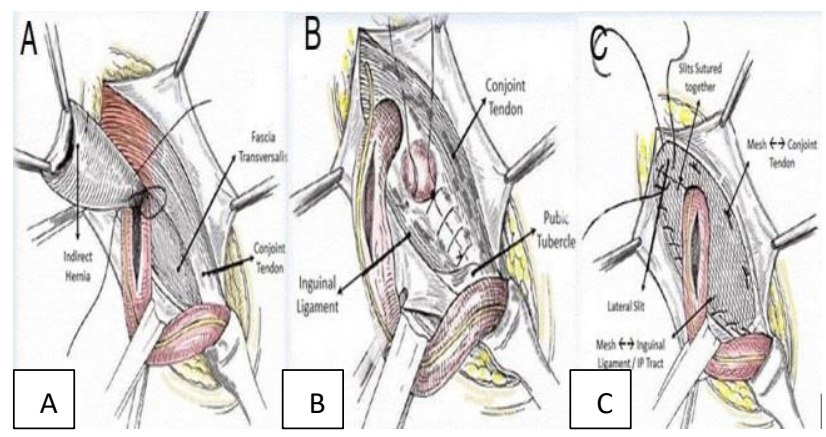

Figure 4: Open herniotomy with mesh repair. A:

Indirect hernia being inspected before excision. B:

Reinforcement of posterior wall of inguinal canal. D: Fixing the mesh on the posterior wall. ${ }^{8}$ 
Jaboulay's technique started with and incision in the tunica vaginalis through which the hydrocele fluid is drained. The testis is delivered through the incision and then most of the hydrocele sac is resected, leaving a small cuff along the borders of the testis and the epididymis. The remnant is everted posteriorly and the tunical edges are reapproximated in a running fashion. Care must be taken to ensure that the closure is loose enough that the spermatic cord is not constricted. The sac is punctured to allow aspiration of the hydrocele fluid. Then, the tunica vaginalis is gently freed and delivered out of the small scrotal incision by applying gentle traction. After fully mobilizing and delivering the hydrocele sac, it is excised by electrocautery, and the wound is closed without the need to deliver the testis. ${ }^{9}$

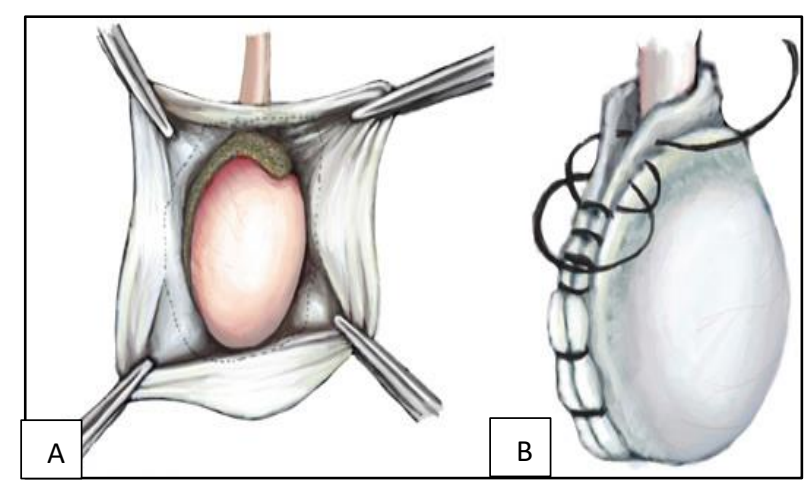

Figure 5: Jaboulay's procedure. A: The hydrocele sac is resected, leaving 1- to $2 \mathrm{~cm}$ cuff along the borders of the testis and epididymis. B: The edges are everted posteriorly around the cord and reapproximated by a running suture. ${ }^{9}$

Later, orchiopexy was performed to ensure that spermatic cord and its contents were correctly inserted into the scrotal sac in their normal anatomical location prior to final surgical closure.

Failure to treat hydroceles can lead to several different complications, including: compression of the testis which can lead to postero-inferior displacement that initially can be painless but later can cause scrotal pain and eventual testicular atrophy secondary to calcification or pressure effect, and hydrocele transformation into a haematocele or pyelocele due to infection. ${ }^{2}$

Funding: No funding sources

Conflict of interest: None declared

Ethical approval: Not required

\section{REFERENCES}

1. Öberg S, Andresen K, Rosenberg J. Etiology of inguinal hernias: A comprehensive review. Front Surg. 2017;4:52.

2. Shah S, Shah P. Modified should ice repair of bilateral inguinal hernia with hydrocele: A case report. South East Asia J Public Health. 2017;7(1):62-5.

3. Agbakwuru EA, Salako AA, Olajide AO, Takure AO, Eziyi AK. Hydrocelectomy under local anaesthesia in a Nigerian adult population. Afr Health Sci. 2008;8(3):160-2.

4. Han BH, Cho JY, Cho BJ, Ki WW. Hydrocele of the spermatic cord ultrasonograhic findings. J Korean Soc Med Ultrasound. 2002;21:129-33.

5. Ku HJ, Kim ME, Lee NK, Park YH. The excisional, placation and internal drainge techniques: a comparison of the results for idiopathic hydrocele. BJU Int. 2001;87:82-4.

6. Manimaran D, Karthikeyan T, Khan D. Encysted spermatic cord hydrocele in a 60-year-old, mimicking incarcerated inguinal hernia: A Case Report. J Clin Diagn Res. 2014;8(2):153-4.

7. Parks K, Leung L. Recurrent Hydrocele. J Family Med and Prim Care. 2013;2(1):109-10.

8. Epomedicine.com. Inguinal Hernia. Available from: https://epomedicine.com/medical-students/herniainguinal-hernia. Accessed on 2 December 2020.

9. Keane TE, Graham SD, Dajaba AA, Tanrikut C. Glen's Urologic Surgery. Philadelphia: Wolters Kluwer. 2016;8.

Cite this article as: Sudiatmika DG, Jayningrum IGAAB. Right funicular hydrocele accompanied by in adverted lateral inguinal hernia finding in geriatric male patient during operation: a case report. Int J Res Med Sci 2021;9:899-901. 